Revue Française de Civilisation Britannique

\title{
David WEIGALL, International Relations: A Concise
}

\section{Companion}

London: Arnold, 2002

\section{Richard Davis}

\section{OpenEdition \\ Journals}

Édition électronique

URL : http://journals.openedition.org/rfcb/3201

DOI : $10.4000 /$ rfcb.3201

ISSN : 2429-4373

Éditeur

CRECIB - Centre de recherche et d'études en civilisation britannique

\section{Édition imprimée}

Date de publication : 1 avril 2003

ISBN : 2-911580-16-8

ISSN : 0248-9015

Référence électronique

Richard Davis, « David WEIGALL, International Relations: A Concise Companion », Revue Française de Civilisation Britannique [En ligne], XII-2 | 2003, mis en ligne le 01 avril 2003, consulté le 24 septembre 2020. URL : http://journals.openedition.org/rfcb/3201 ; DOI : https://doi.org/10.4000/rfcb.3201

Ce document a été généré automatiquement le 24 septembre 2020.

\section{c) $(\$ \ominus$}

Revue française de civilisation britannique est mis à disposition selon les termes de la licence Creative Commons Attribution - Pas d'Utilisation Commerciale - Pas de Modification 4.0 International. 


\title{
David WEIGALL, International Relations: A Concise Companion
}

\author{
London: Arnold, 2002
}

Richard Davis

\section{RÉFÉRENCE}

David WEIGALL, International Relations: A Concise Companion, London: Arnold, 2002, 256p.

ISBN 0340763329 et 0340763337.

1 David Weigall a sans doute raison d'affirmer que l'intérêt pour les questions de politique internationale n'a jamais été aussi grand qu'aujourd'hui. Avec les problèmes de guerre, de famine, de menaces terroristes et de globalisation que connaît le monde actuellement, le moment semble propice à ce genre d'ouvrage. D'autres dictionnaires spécialisés ont été publiés par le passé mais, comme le souligne l'auteur, les grands changements qui ont transformé le monde depuis la fin des années 1980 nécessitent un nouveau regard.

2 Selon l'auteur lui-même l'objectif de ce manuel est d'aider les étudiants en relations internationales et en histoire moderne et contemporaine, ainsi que tous ceux qui s'intéressent aux événements dans le monde, à comprendre des événements complexes pour lesquels la terminologie est parfois difficile et en constante évolution. Avec 1500 références, allant d' $A B C$ states' (l'Argentine, le Brésil et le Chili) et 'ABC weapons' (les armes atomiques, biologiques et chimiques) à 'Zero Sum Game' et 'Zones of Turmoil', cet ouvrage fournit une liste exhaustive de définitions des termes, concepts, théories, organismes, mouvements, traités et doctrines qui couvrent les domaines militaires, juridiques, environnementaux et diplomatiques.

3 Les 1500 définitions de ce livre couvrent une large période depuis 1789, certaines remontant même au siècle précédent avec 'Hobbesian' et 'Grotian'. Parmi les plus récentes on trouve la 'Clinton Doctrine' et des références au 11 septembre. $\mathrm{Si}$, pour la plupart, les termes et concepts expliqués sont utilisés depuis longtemps en politique 
internationale, Weigall n'a pas négligé les termes plus contemporains ('ethnic cleansing', 'Chemical and Biological Weapons' ou 'CBW', et 'Weapons of Mass Destruction') essentiels pour la compréhension des débats actuels. La transformation du monde depuis la chute du mur de Berlin, qui a été accompagnée par l'arrivée d'expressions et de termes nouveaux, souligne l'utilité de cet ouvrage pour les étudiants et les enseignants. Toutefois, si ces changements continuent à la même vitesse dans les années à venir, on peut se demander si cet ouvrage ne devra pas être révisé et re-édité régulièrement.

4 Si les 247 pages de définitions de ce livre paraissent bien utiles, on peut cependant regretter quelques lacunes. Le choix des éditeurs de ne pas inclure les biographies des principaux acteurs peut s'expliquer par un simple manque de place, mais il est néanmoins à regretter. Une telle liste aurait été d'une grande utilité surtout pour les étudiants de civilisation souvent confrontés à des noms peu connus de la plupart d'entre eux. Une bibliographie courte en fin d'ouvrage, avec des sites Internet, présente des ouvrages essentiels en langue anglaise de l'histoire internationale contemporaine et des théories des relations internationales. Par contre, les quelques cartes qui s'y trouvent ne comportent pas de dates et sont étrangement incomplètes. L'URSS, la Yougoslavie et la Tchécoslovaquie y figurent encore mais pas la Russie et les autres nouvelles républiques issues de ces pays qui ont fait leur apparition depuis quelques années. Pourquoi ne pas avoir une carte de l'Europe centrale et orientale post-1990? Pourquoi rien sur l'Asie centrale, une région essentielle s'il en est dans le monde actuel ? La mention 'Angleterre' au lieu de 'Grande-Bretagne' ou 'Royaume-Uni' est également à regretter. Les cartes du Moyen-Orient montrent bien les changements apparus dans cette région après 1945, mais pourquoi s'arrêter en 1967 ?

5 Malgré ces réserves, ce livre est présenté avec une clarté remarquable. Quand il existe diverses interprétations Weigall les présente et les explique de façon précise. Le livre de Weigall ne se contente pas de donner les termes purement historiques ou qui portent sur des relations internationales, mais inclut également des termes relatifs à l'environnement, aux droits de l'homme et aux domaines humanitaires, juridiques, militaires ou diplomatiques, l'approche et l'objectif étant interdisciplinaires. Le grand nombre de références d'origine étrangère est également le bienvenu. D"Acquis communautaire' et 'Aggiornamento' à 'Perestroika', 'Rebus Sic Santibus', 'Tous azimuts' et ' Zeitgeist', cet ouvrage montre l'importance des termes venus d'autres langues, ce qui est encore le cas aujourd'hui, malgré la domination croissante de la langue anglaise sur la scène internationale, et évite une approche exclusivement anglo-américaine (ce qui n'est pas, malheureusement, le cas de la bibliographie fournie par Weigall qui ne compte que des ouvrages en anglais). Weigall a le mérite d'inclure ces mots étrangers qui ont été intégrés dans la langue anglaise et parfois d'ajouter l'origine de mots comme 'Chauvinism' (d'un certain Nicolas Chauvin, le prototype du soldat fanatique qui combattait sous Napoléon) et 'Haves and Have Nots' (de Cervantès).

6 Le livre de David Weigall est sans doute destiné essentiellement à un public d'étudiants en politique internationale, en histoire moderne et contemporaine et en civilisation britannique et américaine. Il sera également un ouvrage de référence indispensable pour toute bibliothèque universitaire. Si l'utilité pour les experts de ces questions est peut-être moins évidente (la plupart des références seront sans doute connues) ce livre reste néanmoins passionnant. Avec une présentation claire, des définitions succinctes et complètes, le tout écrit dans une langue précise, il fournira une aide réelle à tous ceux qui s'intéressent aux relations internationales. 


\section{AUTEURS}

RICHARD DAVIS

Université de Lille III 